\title{
PERFORMANCE COMPARISON OF QOS BASED ROUTING PROTOCOLS MBRR, REAR AND SPEED FOR WIRELESS SENSOR NETWORKS
}

\author{
Deepak Verma ${ }^{1}$, Amardeep Kaur ${ }^{2}$ \\ ${ }^{1}$ M.Tech (C.S.E.), Student, ${ }^{2}$ Assistant Professor (C.S.E.), Punjabi University Regional Center for Information Technology \\ and Management, Mohali, Punjab, India
}

\begin{abstract}
A wireless sensor network (WSN) is a collection of small randomly dispersed micro sensor nodes that have capability to sense, establish wireless communication between each other and do computations and process operations. A network especially wireless network strongly depends on the routing protocols to route the sensed data to the Base Station (BS) via some intermediate nodes. Due to fast emergence of the wireless sensing, a lot of work has been done on the various categories of routing protocols of WSN like location-based, data-centric, hierarchal routing protocols etc. to measure the network performance. But recent studies are provided with the evidence that Quality-of-Service $(Q o S)$ routing can enhance the network performance by increasing the network utilization, compared to routing that is not sensitive to QoS requirements of traffic. So in this paper, the focus is on evaluation and comparison of the network performance in the WSN having QoS routing. The comparison of the three QoS routing protocols MBRR (Majority Based Re-Routing), REAR (Reliable Energy Aware Routing) and SPEED (Stateless Protocol for End-to-End Delay) on the basis of various performance metrics such as Bit Error Rate (BER) vs. Signal-to-Noise Ratio (SNR), Average End-to-End Delay vs. BER, Packet Delivery Ratio vs. BER, Energy Consumed vs. BER, Network Lifetime vs. Energy Consumption, Throughput vs. BER and Throughput vs. SNR has been done in this research paper. On the basis of observed simulation results, it is concluded that the performance of MBRR is better than the performance of other two comparing protocols i.e. REAR and SPEED.
\end{abstract}

Index Terms: Wireless Sensor Networks, Routing Protocols, QoS Routing, and Performance Evaluation etc. $* * *$

\section{INTRODUCTION}

Wireless Sensor Networks (WSNs) have recently drawn significant research attention due to its wide range of applications that may not need human supervision. A Wireless Sensor Networks (WSN) is a set of hundreds or thousands of micro sensor nodes that provide the ability to sense and store the physical and the environmental conditions, often in real time, such as temperature, pressure, light and humidity [1]. Each node is connected to one or several sensors. The size of these sensor nodes is very small. Sensor networks have a wide variety of applications that depends on the variation of requirements and characteristics. The sensor networks can be used in a vast variety of fields like military environment, disaster management, habitat monitoring, medical and health care etc. [2]. Power constraints, limited hardware, decreased reliability, and a typically higher density and number of failure nodes are few of the problems that have to be considered while developing the protocols for use in sensor networks [3]. Due to fast emergence of the wireless sensing, a lot of work has been done on the various categories of routing protocols of WSN like location-based, data-centric, hierarchal routing protocols etc to measure the network performance. But recent studies are provided with the evidence that Quality-of-Service
(QoS) routing can enhance the network performance by increasing the network utilization, compared to routing that is not sensitive to QoS requirements of traffic. So the primary focus here is on evaluating and comparing the network performance in the WSN having QoS routing.

QoS routing is the process of the selection of the path to be used by the flow of packets, based on its QoS requirements, e.g., bandwidth, throughput etc. In QoS based routing, the protocols provide different priorities to different applications, users, or data flows, or to guarantee a certain level of performance to a data flow [4]. There are so many routing protocols in the QoS-based routing protocols like SAR (Sequential Assignment Routing) [4], SPEED (Stateless Protocol for End-to-End Delay) [7], MMSPEED (Multipath Multi SPEED) [4], Energy-aware routing protocol [4], TBRR (A Tree-Based Reliable Routing Protocol) [8], REAR (Reliable Energy Aware Routing) [6], MBRR (Majority Based Re-Routing) [5], PISA(Priority-based path Selection Algorithm) [5] [8], PISA-III [5] [8], SBRR (Score Based Reliable Routing) [5] [8] etc. The main QoS-based routing protocols that are under consideration in this paper are MBRR, REAR and SPEED as discussed in the following section. 


\subsection{MBRR (Majority Based Re-Routing)}

MBRR classifies the data into differentiated classes using a decision-making function called Win and then routes the datapackets towards the sink node in a highly reliable way. Moreover, MBRR engages a new adaptive approach called majority based re-routing approach in order to route the datapackets with instantaneously change in number intimating occurrence of special events via some more reliable paths [5].

\subsection{REAR (Reliable Energy Aware Routing)}

REAR is designed and implemented on the Nano-Qplus platform to overcome the energy constraint issues in the WSN. To establish routing paths in the network, REAR considers the residual energy capacity of each sensor node and it also supports the multi-path routing for reliable data transmission in WSN. Moreover, the REAR also supports the DATA-ACK oriented packet transmission, to confirm success of data transmission from one sensor node to other [6].

\subsection{SPEED (Stateless Protocol for End-to-End Delay)}

SPEED (Stateless Protocol for End-to-End Delay) is a protocol of real-time communication for sensor networks. It is specifically designed to be a stateless, localized algorithm with minimum control overhead. In SPEED, real-time communication is achieved by sustaining a desired delivery speed across the sensor network through a novel combination of feedback control and non-deterministic geographic forwarding. SPEED retains a desired delivery speed across sensor networks by both diverting traffic at the networking layer and locally regulating packets sent to the MAC layer [7].

\section{RELATED WORK}

Various authors have proposed and discussed number of QoS routing protocols and analyzed their performance in WSN.

S. M. Mazinani et al. [8] proposed a new QoS based routing protocol called tree-based routing protocol (TBRR) that provides a high reliability in routing packets towards the destination node. The author has also compared the performance of the TBRR with three other QoS based protocols called PISA-III, SBRR and REAR using MATLAB and $\mathrm{C}++$ simulation frameworks. The simulation results show that the TBRR minimizes the energy consumption, shows the minimum amount of reduction in packet delivery ratio and yields less average packet latency as the percentage of nodes with high channel error rate increases as compared to all the other three protocols.

A. Naderi et al. [5] focused on building a routing protocol called MBRR which classifies the data into differentiated classes using a decision-making function called Win and then routes the data-packets towards the sink node in a highly reliable way. Moreover, MBRR engages a new adaptive approach called majority based re-routing approach in order to route the data-packets with instantaneously change in number intimating occurrence of special events via some more reliable paths. The paper demonstrated that MBRR protocol exhibits a better performance in regards of total energy consumption, Packet Delivery Ratio and Packet Delivery Ratio as percentage of nodes with high channel error-rate increases and when operating in a noisy wireless environment along with node failure, as compared to PISA-III, REAR, LEQR and SBRR protocols.

R. Sumathi et al. [9], presented the state of the research by summing up the work on QoS routing protocols. The performance of QoS based protocols like SAR, MMSPEED, MCBR, MCMP, and EQSR is also analyzed for various parameters using NS2 in this paper. The simulation result shows that EQSR achieves good reliability, saves more energy and shows lesser control packet overhead than other algorithms and increases the network lifetime due to energy efficiency. Furthermore, EQSR distributes the traffic load over spatially distributed nodes.

M. A. Koulali et al. [10], suggested a hybrid QoS based routing protocol for wireless sensor networks based on a customized Distributed Genetic Algorithm (DGA) that accounts for delay and energy constraints. The suggested protocol QDGRP (i.e. QoS Distributed Genetic Routing Protocol) supports QoS constraints on end-to-end delay and sensor's residual energy. The realized simulations show that QDGRP shows better results than AODV in terms of delay, throughput, and packet delivery ratio.

J. Sen et al. [11], presented a query-based routing protocol for a WSN that provides different levels of Quality of Service (QoS) such as energy-efficiency, reliability, and faulttolerance-under different application scenarios. The algorithm is implemented in network simulator ns-2 and its performance has been evaluated. As the results of the proposed algorithm are compared with some of the currently existing routing algorithms, it comes to know that the proposed algorithm is more efficient in terms of average dissipated energy in sensor nodes and average latency in message communication.

S. Chimkode et. al. [12], proposed a Reliable and Robust QoS Routing Protocol (RRQRP) for WSNs based on a Combined Weight $(\mathrm{CW})$ Value which is assigned to each link and based on the QoS metrics like link quality, available bandwidth, and residual energy. In order to avoid link failures, the value of the $\mathrm{CW}$ of each node is measured with the help of monitoring agent (MA) placed at intermediate node. This calculated CW is then compared with the MCW (Minimum Combined Weight). If $\mathrm{CW}$ value is lesser than $\mathrm{MCW}$, then a warning message is sent to the source to select an alternate path. In order to avoid congestion losses, the author has also presented an adaptive rate control mechanism. And the performance of the proposed protocol RRQRP is compared with the performance of the QoS Based Routing protocol (QBRP), 
using the simulator NS2. The simulation results show that proposed protocol RRQRP achieves high throughput with reduced energy consumption and delay, and thus it shows more reliability and robustness when compared to existing protocols.

\section{QOS METRICS}

MATLAB supports different parameters for the measurement performance evaluation of the WSN under different routing protocols. The metrics used are Bit Error Rate (BER) vs. Signal-to-Noise Ratio (SNR), Average end-to-end delay vs. BER, Packet Delivery Ratio vs. BER, Energy Consumed vs. BER, Network Lifetime vs. Energy Consumption, Throughput vs. BER, and Throughput vs. SNR. The table of the metrics with their details, used to evaluate the performance of the routing protocols is given below in Table 1:

Table -1: Description of the QoS Metrics

\begin{tabular}{|c|c|c|}
\hline $\begin{array}{l}\text { Sr. } \\
\text { No }\end{array}$ & QoS Metrics & Description \\
\hline 1 & $\begin{array}{l}\text { Bit Error Rate } \\
\text { (BER) } \\
\text { (measured in } \\
\text { \%age) }\end{array}$ & $\begin{array}{l}\text { BER is number of bit errors } \\
\text { divided by total number of } \\
\text { transferred bits in a specified time } \\
\text { interval [15]. }\end{array}$ \\
\hline 2 & $\begin{array}{l}\text { Average End-to- } \\
\text { End Delay } \\
\text { (expressed in } \\
\text { seconds) }\end{array}$ & $\begin{array}{l}\text { It is the time taken by a data } \\
\text { packet to be transmitted across a } \\
\text { network from source to } \\
\text { destination [13]. }\end{array}$ \\
\hline 3 & $\begin{array}{l}\text { Packet Delivery } \\
\text { Ratio } \\
\text { (expressed in } \\
\text { number } \\
\text { packets) }\end{array}$ & $\begin{array}{l}\text { It is the ratio of total number of } \\
\text { delivered packets successfully } \\
\text { received by the sink node to the } \\
\text { number of packets sent by all } \\
\text { sensor nodes in the network [13]. }\end{array}$ \\
\hline 4 & $\begin{array}{l}\text { Energy } \\
\text { Consumed } \\
\text { (measured } \\
\text { KJ) }\end{array}$ & $\begin{array}{l}\text { It is a measure of rate at which } \\
\text { energy is dissipated by sensor } \\
\text { nodes in a WSN within a specific } \\
\text { time period [13]. }\end{array}$ \\
\hline 5 & $\begin{array}{l}\text { Network } \\
\text { Lifetime } \\
\text { (measured } \\
\text { minutes) }\end{array}$ & $\begin{array}{l}\text { The lifetime of a WSN can be } \\
\text { defined as the time elapsed until } \\
\text { the first node dies, the last node } \\
\text { dies, or a fraction of nodes dies } \\
\text { [14] }\end{array}$ \\
\hline 6 & $\begin{array}{l}\text { Average } \\
\text { Network } \\
\text { Throughput } \\
\text { (measured in } \\
\text { bps i.e. bits per } \\
\text { seconds) }\end{array}$ & $\begin{array}{l}\text { It is the average number of data } \\
\text { packets successfully received by } \\
\text { the sink node per unit time [13]. }\end{array}$ \\
\hline
\end{tabular}

\begin{tabular}{|l|l|l|}
\hline \multirow{7}{*}{7} & $\begin{array}{l}\text { It is described as the ratio of } \\
\text { signal strength to the noise } \\
\text { Signal-to-Noise } \\
\text { Ratio (SNR) } \\
\text { (expressed in db } \\
\text { i.e. decibels) }\end{array}$ & $\begin{array}{l}\text { strength. A ratio higher than 1:1 } \\
\text { (greater than 0 dB) denotes more } \\
\text { signal than noise [16]. }\end{array}$ \\
\hline
\end{tabular}

\section{SIMULATION RESULTS \& DISCUSSIONS}

The simulation is carried out using MATLAB simulation tool. Two scenarios are being used to simulate the routing protocols. First scenario contains 10 wireless sensor nodes and in the second scenario 20 wireless sensor nodes are taken. The same network environment factors are configured for both the scenarios. The performance evaluation is done by simulating both the scenarios one by one in the MATLAB simulator and results in the form of graphs are obtained. The simulation area is $50 \mathrm{~m} * 50 \mathrm{~m}$ and the general distance between the sensor nodes is $30 \mathrm{~m}$. The simulation results of various routing protocols are discussed below.

The protocol MBRR introduces the lowest BER in the network as the SNR increases in both the scenarios (Figure 1 \& Figure 2) comparing to REAR and SPEED protocols.

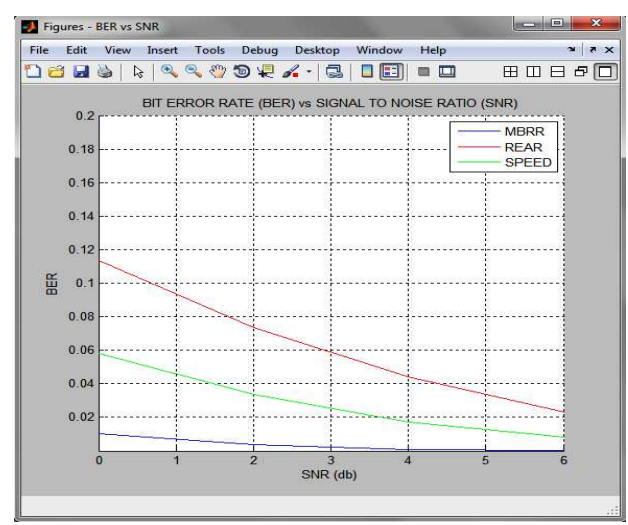

Fig -1: BER vs SNR for Scenario 1

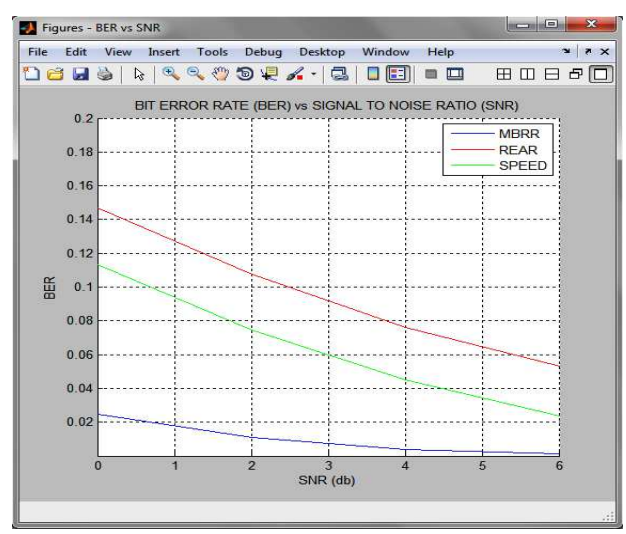

Fig -2: BER vs SNR for Scenario 2 
The MBRR protocol shows the lowest and REAR introduces the maximum Average End-to-End Delay as the BER increases in the both the scenarios (Figure 3 \& Figure 4).

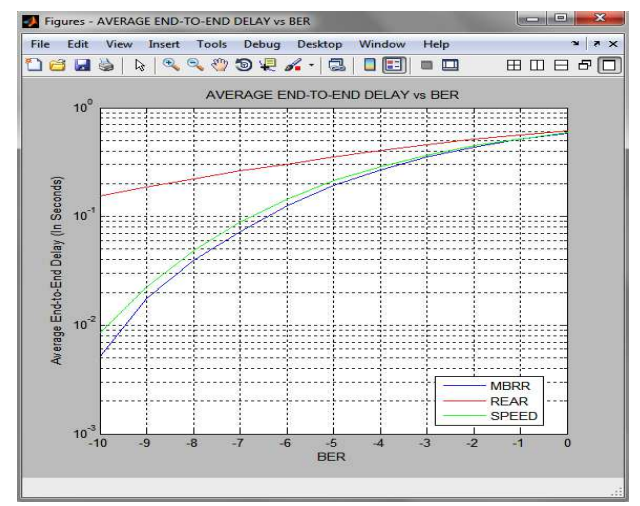

Fig -3: Average End to End Delay vs BER for Scenario 1

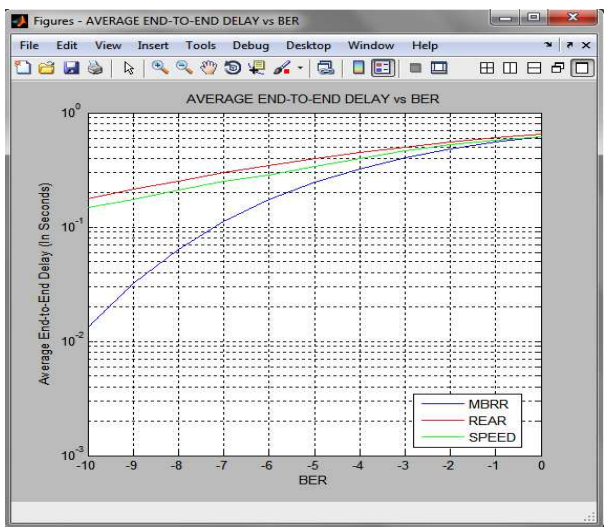

Fig -4: Average End to End Delay vs BER for Scenario 2

As shown in the Figure 5 and Figure 6, the MBRR protocol shows the best performance in terms of the Packet Delivery Ratio as compared to the other two protocols. MBRR shows the highest and REAR shows the lowest Packet Delivery Ratio as BER increases in both the scenarios.

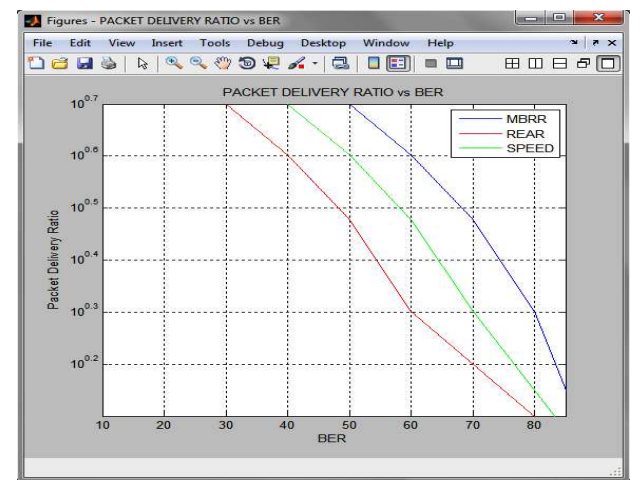

Fig -5: Packet Delivery Ratio vs BER for Scenario 1

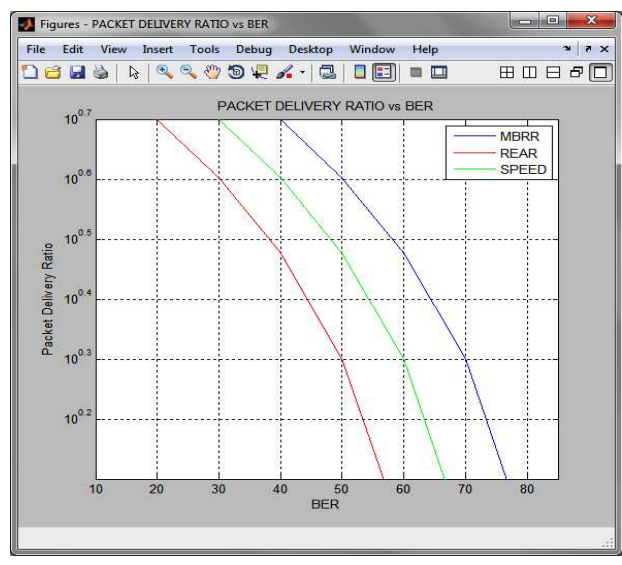

Fig -6: Packet Delivery Ratio vs BER for Scenario 2

As shown in the Figure $7 \&$ Figure 8, the MBRR protocol shows the best and the SPEED protocol shows the worst performance in terms of the Energy Consumption as the BER increases in both the scenarios.

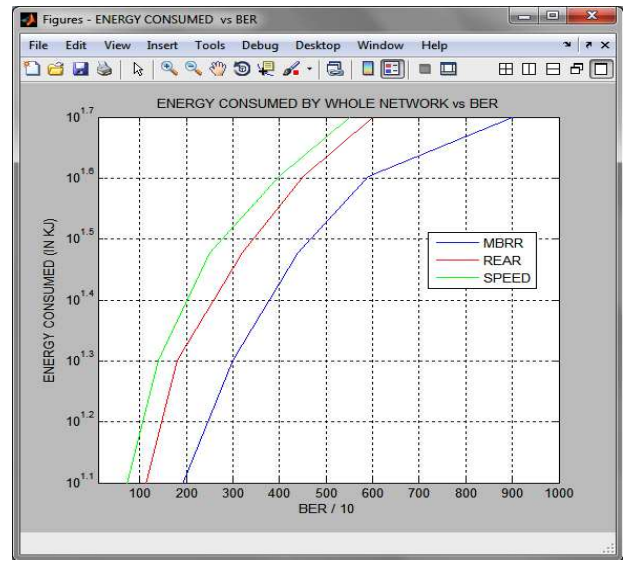

Fig -7: Energy Consumed vs BER for Scenario 1

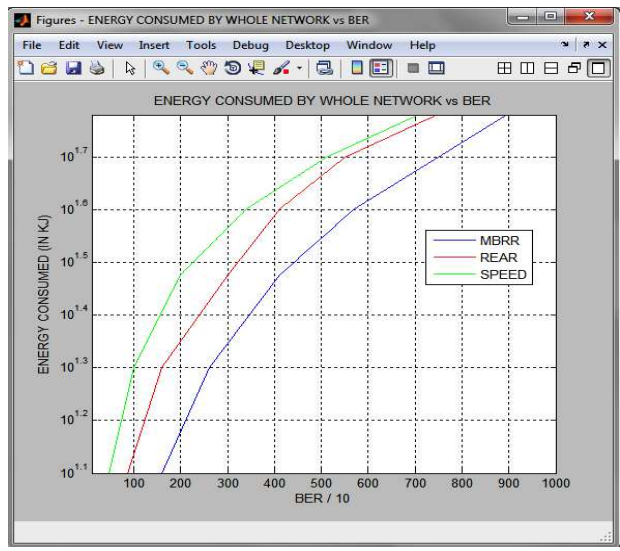

Fig -8: Energy Consumed vs BER for Scenario 2 
The Network Lifetime of WSN is evaluated in Figure $9 \&$ Figure 10 for each of the three comparing protocols as the Energy Consumption by the sensor nodes in the WSN increases. Here again the MBRR protocol in both the scenarios outperforms the other two protocols with the maximum Network Lifetime.

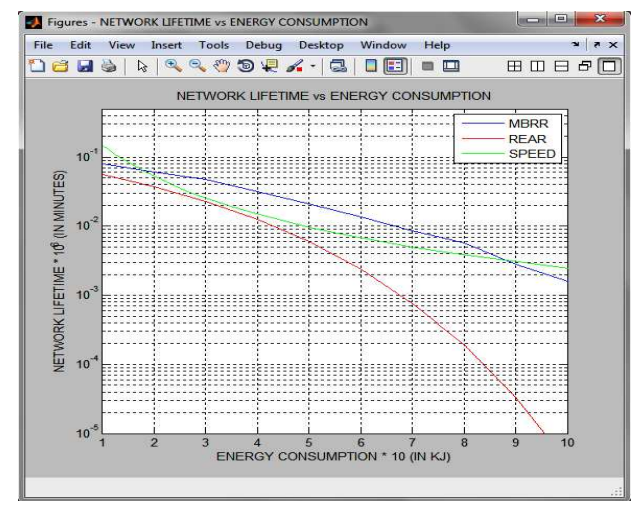

Fig -9: N/w Lifetime vs Energy Consumption for Scenario 1

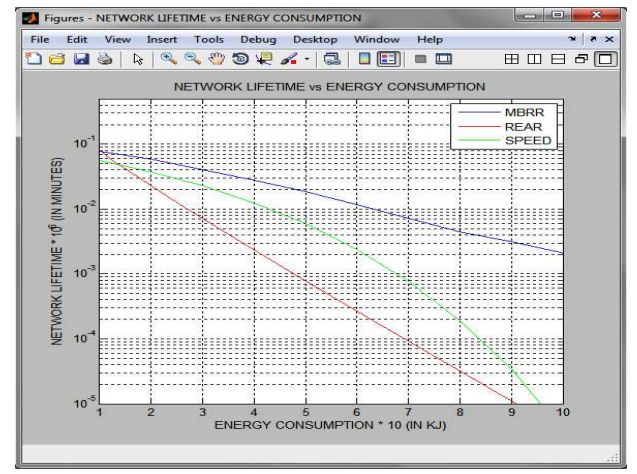

Fig -10: N/w Lifetime vs Energy Consumption for Scenario 2

As shown in the Figure 11 \& Figure 12, MBRR protocol shows the best results in terms of the throughput as the BER increases in both the scenarios. SPEED and REAR protocols show the moderate and worst results for throughput.

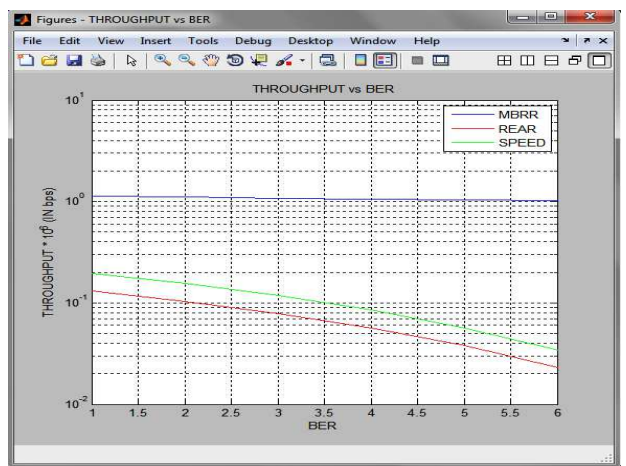

Fig -11: Throughput vs BER for Scenario 1

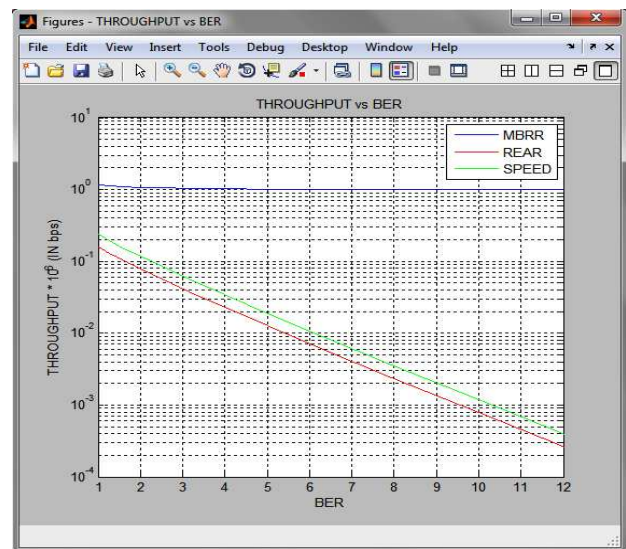

Fig -12: Throughput vs BER for Scenario 2

This time the performance of the each of the three protocols is evaluated on the basis of the throughput as the SNR increases as shown in the Figure 13 \& Figure 14. MBRR protocol shows the best results in terms of the throughput as the SNR increases in both the scenarios.

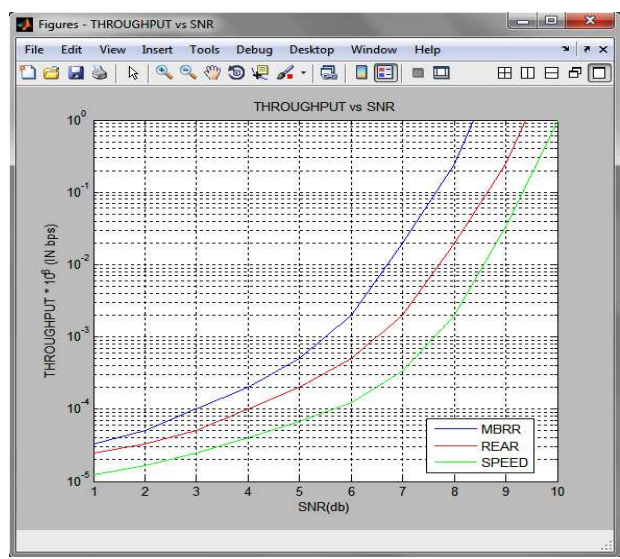

Fig -13: Throughput vs SNR for Scenario 1

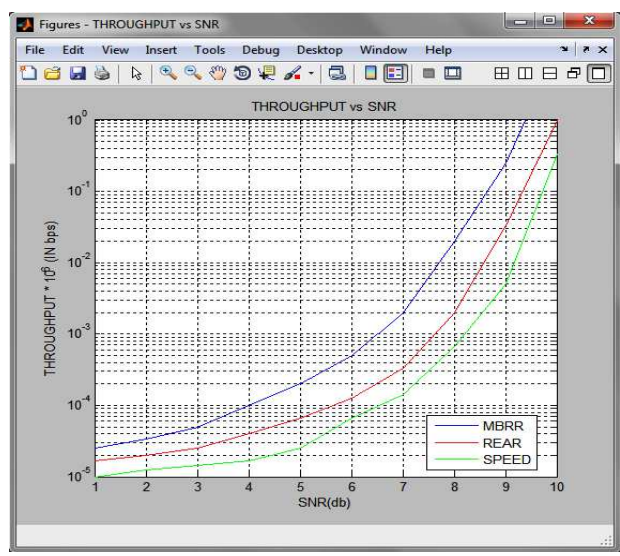

Fig -14: Throughput vs SNR form Scenario 2 
The brief discussions of the results are represented in the form of the tables, shown below. The Table 2 includes the discussions for the results of the simulation scenario 1 and the Table 3 includes the discussions for the results of the simulation scenario 2 .

Table -2: Simulation Scenario 1

\begin{tabular}{|l|l|l|l|}
\hline Metrics & MBRR & REAR & SPEED \\
\hline $\begin{array}{l}\text { BER (At 0 db } \\
\text { SNR) }\end{array}$ & $\begin{array}{l}0.01046 \\
\%\end{array}$ & $0.1134 \%$ & $\begin{array}{l}0.05805 \\
\%\end{array}$ \\
\hline $\begin{array}{l}\text { Delay (At 0\% } \\
\text { BER) }\end{array}$ & $\begin{array}{l}0.5824 \\
\text { seconds }\end{array}$ & $\begin{array}{l}0.6165 \\
\text { seconds }\end{array}$ & $\begin{array}{l}0.5866 \\
\text { seconds }\end{array}$ \\
\hline $\begin{array}{l}\text { Delivery Ratio } \\
\text { (At 50\% BER) }\end{array}$ & 5 packets & 3 packets & 4 packets \\
\hline Metrics & MBRR & REAR & SPEED \\
\hline $\begin{array}{l}\text { Energy } \\
\begin{array}{l}\text { Consumed (At } \\
\text { 20\% BER) }\end{array}\end{array}$ & $12.88 \mathrm{KJ}$ & $20.89 \mathrm{KJ}$ & $25.11 \mathrm{KJ}$ \\
\hline $\begin{array}{l}\text { Network (At 20 } \\
\text { Lifetime } \\
\text { KJ Energy } \\
\text { Consumption) }\end{array}$ & $\begin{array}{l}61600 \\
\text { minutes }\end{array}$ & $\begin{array}{l}37510 \\
\text { minutes }\end{array}$ & $\begin{array}{l}53000 \\
\text { minutes }\end{array}$ \\
\hline $\begin{array}{l}\text { Throughput (At } \\
1 \% \text { BER) }\end{array}$ & $\begin{array}{l}1104^{*} 10 \\
\wedge 3 \text { bps }\end{array}$ & $\begin{array}{l}104^{*} 10^{\wedge} \\
3 \text { bps }\end{array}$ & $\begin{array}{l}156^{*} 10^{\wedge} \\
3 \text { bps }\end{array}$ \\
\hline $\begin{array}{l}\text { Throughput (At } \\
8 \text { db SNR) }\end{array}$ & $\begin{array}{l}25^{*} 10^{\wedge} 4 \\
\text { bps }\end{array}$ & $\begin{array}{l}2^{*} 10^{\wedge} 4 \\
\text { bps }\end{array}$ & $\begin{array}{l}2^{*} 10^{\wedge} 3 \\
\text { bps }\end{array}$ \\
\hline
\end{tabular}

Table -3: Simulation Scenario 2

\begin{tabular}{|l|l|l|l|}
\hline Metrics & MBRR & REAR & SPEED \\
\hline $\begin{array}{l}\text { BER (At 0 db } \\
\text { SNR) }\end{array}$ & $\begin{array}{l}0.02487 \\
\%\end{array}$ & $0.1468 \%$ & $0.1132 \%$ \\
\hline $\begin{array}{l}\text { Delay (At 0\% } \\
\text { BER) }\end{array}$ & $\begin{array}{l}0.618 \\
\text { seconds }\end{array}$ & $\begin{array}{l}0.6522 \\
\text { seconds }\end{array}$ & $\begin{array}{l}0.622 \\
\text { seconds }\end{array}$ \\
\hline $\begin{array}{l}\text { Delivery Ratio } \\
\text { (At 50\% BER) }\end{array}$ & 4 packets & 2 packets & 3 packets \\
\hline $\begin{array}{l}\text { Energy } \\
\text { Consumed (At } \\
\text { 20\% BER) }\end{array}$ & $15.13 \mathrm{KJ}$ & $22.38 \mathrm{KJ}$ & $29.51 \mathrm{KJ}$ \\
\hline Metrics & MBRR & REAR & SPEED \\
\hline $\begin{array}{l}\text { Network (At 20 } \\
\text { Lifetime } \\
\text { KJ Energy } \\
\text { Consumption) }\end{array}$ & $\begin{array}{l}59000 \\
\text { minutes }\end{array}$ & $\begin{array}{l}22880 \\
\text { minutes }\end{array}$ & $\begin{array}{l}37510 \\
\text { minutes }\end{array}$ \\
\hline $\begin{array}{l}\text { Throughput (At } \\
\text { 2\% BER) }\end{array}$ & $\begin{array}{l}1079 * 10 \\
\wedge 3 \text { bps }\end{array}$ & $\begin{array}{l}789^{*} 10^{\wedge} \\
2 \text { bps }\end{array}$ & $\begin{array}{l}1183 * 10 \\
\wedge 2 \text { bps }\end{array}$ \\
\hline $\begin{array}{l}\text { Throughput (At } \\
8 \text { db SNR) }\end{array}$ & $\begin{array}{l}2 * 10^{\wedge} 4 \\
\text { bps }\end{array}$ & $\begin{array}{l}2 * 10^{\wedge} 3 \\
\text { bps }\end{array}$ & $\begin{array}{l}666.7 \\
\text { bps }\end{array}$ \\
\hline
\end{tabular}

Table 4 shows the discussions for the results of comparing the relative performance of both the scenarios.
Table -4: Simulation Results in both Scenarios

\begin{tabular}{|c|c|c|c|}
\hline & MBRR & REAR & SPEED \\
\hline $\begin{array}{l}\text { Scena } \\
\text { rio } 1\end{array}$ & $\begin{array}{l}\text { Very High } \\
\text { Throughput, } \\
\text { Minimum } \\
\text { Energy } \\
\text { Consumption } \\
\text { \& Very High } \\
\text { Packet } \\
\text { Delivery Ratio }\end{array}$ & $\begin{array}{l}\text { Average } \\
\text { Throughput, } \\
\text { Average } \\
\text { Energy } \\
\text { Consumption } \\
\text { \& Low } \\
\text { Packet Delivery } \\
\text { Ratio }\end{array}$ & $\begin{array}{l}\text { Average } \\
\text { Throughput, } \\
\text { Very High } \\
\text { Energy } \\
\text { Consumption } \\
\& \quad \text { Average } \\
\text { Packet } \\
\text { Delivery Ratio }\end{array}$ \\
\hline $\begin{array}{l}\text { Scena } \\
\text { rio } 2\end{array}$ & $\begin{array}{l}\text { High } \\
\text { Throughput, } \\
\text { Average } \\
\text { Energy } \\
\text { Consumption } \\
\text { \& High Packet } \\
\text { Delivery Ratio }\end{array}$ & $\begin{array}{l}\text { Low } \\
\text { Throughput, } \\
\text { High Energy } \\
\text { Consumption } \\
\text { \& Very Low } \\
\text { Packet } \\
\text { Delivery } \\
\text { Ratio }\end{array}$ & $\begin{array}{l}\text { Low } \\
\text { Throughput, } \\
\text { Maximum } \\
\text { Energy } \\
\text { Consumption } \\
\text { \& Low Packet } \\
\text { Delivery Ratio }\end{array}$ \\
\hline
\end{tabular}

\section{CONCLUSIONS}

This paper concludes the results in two scenarios where number of nodes varies in these scenarios to observe the variation in the performance of three routing protocols MBRR, REAR, and SPEED of Quality of Service (QoS), deployed over Wireless Sensor Network to analyze their behavior with respect to QoS metrics defined in the section 3. The study of these Wireless Sensor routing protocols shows that the MBRR protocol is the best protocol as per the simulation results of this paper because it shows almost the best performance for all the metrics. MBRR shows the lowest BER as the SNR increases, the lowest Average End-to-End Delay as the BER increases, the highest Packet Delivery Ratio as the BER increases, the lowest Energy Consumption as the BER increases, the highest Network Lifetime as the Energy Consumption increases, the highest Throughput as the BER increases and again the highest Throughput as the SNR increases among the other two comparing routing protocols, in both the scenarios. And the REAR gives the worst performance for almost all the metrics against which the comparison has done, except against the Energy Consumption as the BER increases and the throughput as the SNR increases. And the SPEED protocol gives the moderate results for almost all the metrics, but shows the worst results against the Energy Consumption as the BER increases and the Throughput as the SNR increases. While comparing the results of both the scenarios, it is concluded that the scenario 1 shows the better performance than the scenario 2 . So, it is clear that all the routing protocols show the better performance in the network having less number of sensor nodes as compared to the network having more number of sensor nodes. But, the MBRR protocol also outperforms against each QoS metrics on comparing the results of the both the scenarios among the other two protocols. 
Thus the conclusion of this study is that the MBRR protocol is the best protocol as compared to the other two protocols i.e. REAR and SPEED, as per the simulation results of both the scenarios in this paper, but it is not necessary that MBRR perform always better in all the networks. Performance may vary due to the variation in the network type. At the end we came to the conclusion from the simulation and analytical study of Wireless Sensor Network (WSN) that the performance of the routing protocols changes with network, and the selection of the accurate routing protocol according to the network.

\section{FUTURE SCOPE}

Future scope of this paper is that one can compare the same Wireless Sensor Network routing protocols deployed with some Genetic Algorithms to optimize the performance of these routing protocols against the same metrics or parameters [17]. Also there is scope to introduce Neural Networks technology into the sensor nodes deployed under the same routing protocols of the WSN so that the nodes in the network may be able to use the self-organized maps, to reduce the endto-end delay especially [18].

\section{REFRENCES}

[1] Dr. Praveen Chaturvedi, "Introduction to Wireless Sensor Networks," International Journal of Advanced Research in Computer Science and Software Engineering, vol. 2, iss.10, Oct. 2012

[2] Neha Singh, Prof.Rajeshwar Lal Dua, and Vinita Mathur, "Wireless Sensor Networks: Architecture, Protocols, Simulator Tool," International Journal of Advanced Research in Computer Science and Software Engineering, vol.2, iss.5, May 2012.

[3] Harsh Sundani, Haoyue Li, Vijay K. Devabhaktuni, Mansoor Alam, and Prabir Bhattacharya, "Wireless Sensor Network Simulators a Survey and Comparisons," International Journal of Computer Networks (IJCN), vol.2, iss.5, pp. 249265, Feb. 2011.

[4] Shio Kumar Singh, M P Singh, and D K Singh, "Routing Protocols in Wireless Sensor Networks -A Survey," International Journal of Computer Science \& Engineering Survey (IJCSES), vol.1, no.2, November 2010

[5] Ali Naderi, Sayyed Majid Mazinani, Amin Zadeh Shirazi, and Mahya Faghihnia, "Adaptive Majority-Based Re-Routing For Differentiated Reliability In Wireless Sensor Networks," IEEE 17th International Conference on Engineering of Complex Computer Systems, July 2012

[6] Kee-Young Shin, JunKeun Song, JinWon Kim, Misun Yu, and Pyeong Soo Mah, "REAR: Reliable Energy Aware Routing Protocol for Wireless Sensor Networks," in proceedings of 9th International Conference on Advanced Communication Technology, vol. 1, pp.525-530, Feb.2007.

[7] Tian He, John A Stankovica, Chenyang Lu, and Tarek Abdelzaher, "SPEED: A Stateless Protocol for Real-Time Communication in Sensor Networks," in proceedings of 23rd
International Conference on Distributed Computing Systems, pp. 46-55, May 2003.

[8] Sayyed Majid Mazinani et al., "A Tree-Based Reliable Routing Protocol in Wireless Sensor Networks," IEEE International Symposium on Computer, Consumer and Control (IS3C), pp. 491-494, June 2012.

[9] R.Sumathi, and M.G.Srinivas, "A Survey of QoS Based Routing Protocols for Wireless Sensor Networks," Journal of Information Processing Systems, vol.8, no.4, Dec. 2012.

[10] Koulali, M. et al., "QDGRP: A Hybrid QoS Distributed Genetic Routing Protocol for Wireless Sensor Networks," IEEE International Conference on Multimedia Computing and Systems (ICMCS), pp. 47-52, May 2012.

[11] Jaydip Sen, and Arijit Ukil, "An Adaptable and QoSAware Routing Protocol for Wireless Sensor Networks," IEEE International Conference on Wireless Communication, Vehicular Technology, Information Theory and Aerospace \& Electronics Systems Technology (Wireless VITAE), pp.767771, 2009.

[12] Suresh Chimkode, Ramesh S. Jadhav, and Basavraj S. Mathapati, "A Reliable and Robust QoS Routing Protocol for Mobile Wireless Sensor Networks," International Journal of Computer Applications (0975 - 888), vol. 47, no.14, June 2012

[13] S.C. Chabalala, T.N. Muddenahalli, and F. Takawira, "Energy-Efficient Dynamic Source Routing Protocol for Wireless Sensor Networks," IJCSNS International Journal of Computer Science and Network Security, vol.12, no.10, pp. 98-109, October 2012.

[14] Abdul Sattar Malik, and Suhail A. Qureshi, "Analyzing the Factors Affecting Network Lifetime for Cluster-based Wireless Sensor Networks," Pak. J. Engg \& Appl. Sci., vol. 6, pp. 9-16, Jan. 2010

[15] (Aug.07, 2013) Bit Error Rate [Online]. Available: Website https://en.wikipedia.org/wiki/Bit_error_rate

[16] (Aug.07, 2013) Signal-to-noise Ratio [Online]. Available: Website http://en.wikipedia.org/wiki/Signal-to-noise_ratio

[17] Jin Fan, and D.J. Parish, "Using a Genetic Algorithm to Optimize the Performance of a Wireless Sensor Network," in PG Net, Liverpool, pp.3-8, 2007.

[18] Luis Javier Garcia Villalba, Ana Lucila Sandoval Orozco, Alicia Trivino Cabrera, and Claudia Jacy Barenco Abbas, "Routing Protocols in Wireless Sensor Networks," Sensors (ISSN 1424-8220), vol.9, pp. 8399-8421, Oct. 2009. 